\title{
Optometric Analysis of Color Space and Contrast of Electronic Message Signs
}

\author{
Saiful Azlan Rosli', Nur-Athirah Md-Adnan'1, Cosette-Yoon-Wey Hoe ${ }^{3}$, Ai-Hong Chen ${ }^{1}$ \\ 1 Optometry, Faculty of Health Sciences, \\ Universiti Teknologi MARA (UiTM) Selangor, Puncak Alam Campus, 42300 Puncak Alam, Malaysia, \\ 2 Jeffrey Cheah School of Medicine and Health Sciences, \\ Monash University, Malaysia.
}

saifu12797@uitm.edu.my, athirahteera@gmail.com, cosetteee006@gmail.com, aihong0707@yahoo.com

Tel: +603-32584415

\begin{abstract}
This study aimed to perform optometric analysis of the color space and contrast of electronic message. Four electronic messages with different color spaces and contrast were constructed. Color space was measured by "RGB Sliders" from the menu "Transparency" in the Microsoft Office PowerPoint 2011. The luminance was measured by the luminance meter. The reading speed was recorded as words per minute. Reading speed varies significantly in four different electronic messages with different color space and contrast ratio. The mean reading speed increased significantly from L4 to $L 3$. The highest reading speed was found at the intermediate color space.
\end{abstract}

Keywords: Legibility; color space; luminance; contrast.

eISSN: 2398-4287@ 2020. The Authors. Published for AMER ABRA cE-Bs by e-International Publishing House, Ltd., UK. This is an open access article under the CC BYNC-ND license (http://creativecommons.org/licenses/by-nc-nd/4.0/). Peer-review under responsibility of AMER (Association of Malaysian Environment-Behaviour Researchers), ABRA (Association of Behavioural Researchers on Asians) and cE-Bs (Centre for Environment-Behaviour Studies), Faculty of Architecture, Planning \& Surveying, Universiti Teknologi MARA, Malaysia. DOI: https://doi.org/10.21834/ebpj.v5i15.2494.

\subsection{Introduction}

Information retrieval involves complex cognitive processes of decoding texts or symbols (Hoover \& Gough, 1990b; Jufri et al., 2016; Khalid et al., 2017). Before engaging in any form of information processing, the eye must first identify and read the text. Appropriate lighting enables the text to be visible. At the same time, contrast is what makes it legible. Legibility is about the quality of being clear enough to read. The legibility of the road sign is essential to provide a safer road environment for road users. Road signs are used to regulate traffic, warn drivers, and provide useful information to help make driving safe and convenient. The road signs should be legible sufficiently far away to give advanced notice to road users (Taylor et al., 2013). Electronic-message signs are supplementary to the existing conventional road signs on roadways to give road users information, such as traffic conditions, accidents, roadwork zones, speed limits, guide vehicles to take alternative routes on specific road segments. The legibility of the electronic-message signs is essential to convey the message effectively to road users. Better legibility has been associated with increased contrast (Tinker \& Paterson, 1931). The reading rate was faster for black-on-white text than any other color combination contrast (Tinker \& Paterson, 1931). The reading rate is reduced by two factors when text contrast reduces from $100 \%$ to $10 \%$ (Legge et al., 1990). High contrast between the text and its associated background is essential for efficient reading. Positive text-background polarity has been associated with efficient reading due to high display luminance (Buchner et al., 2009). Insufficient lighting is likely to cause visual discomfort and compromised legibility (Boyce \& Wilkins, 2018). Visual or ocular discomfort has been linked to visual display terminals, spatial structure,

eISSN: 2398-4287C 2020. The Authors. Published for AMER ABRA cE-Bs by e-International Publishing House, Ltd., UK. This is an open access article under the CC BYNC-ND license (http://creativecommons.org/licenses/by-nc-nd/4.0/). Peer-review under responsibility of AMER (Association of Malaysian Environment-Behaviour Researchers), ABRA (Association of Behavioural Researchers on Asians) and cE-Bs (Centre for Environment-Behaviour Studies), Faculty of Architecture, Planning \& Surveying, Universiti Teknologi MARA, Malaysia.

DOI: https://doi.org/10.21834/ebpj.v5i15.2494. 
and perceived naturalness (Jaiswal et al., 2019; Yoshimoto et al., 2020). Inappropriate background luminance triggers discomfort or disability glare (Duchnicky \& Kolers, 1983). Adaptive luminance contrast has been indicated after prolonged exposure (Na \& Suk, 2014). Other than that, the focusing eye system's inaccuracy, which is called the lag of accommodation, increased during the reading task, contributing to the visual problem (Najmee et al., 2020).

\subsection{Literature Review}

\subsection{Legibility and Contrast}

Legibility, either for print or electronic signage, was quantified through visual acuity, commonly used to determine the quality of vision and contrast sensitivity. This parameter was a better marker for visual performance under photopic and scotopic conditions (Rabin, 1993). Photopic condition is when the eye under daylight condition (ranged of luminance level 10 to $10^{8} \mathrm{~cd} / \mathrm{m}^{2}$ ), while scotopic is the vision under the low light condition (ranged of luminance $10^{-2} \mathrm{~cd} / \mathrm{m}^{2}$ ). According to the Michelson formula in Equation 2, the contrast was different between the maximum and minimum luminance of the front and background colors divided by the maximum and minimum luminance of the front and background colors. For text displayed, $L_{\min }$ (luminance minimum) referred to letters while $L_{\max }$ (luminance maximum) referred to white background. The ranges for Michelson contrast began from 0 to 1.0 (Legge et al., 1997). Different contrast of text had displayed increased or decreased in reading rate. The contrast was significant because of various contrasts seen in the environment and ocular disease that can lower the reading rate. It was reported that the reading rate was reduced two times when the contrast of text decreases from $100 \%$ to $10 \%$. However, the reading rate was reduced more significantly for text contrast below $10 \%$ (Legge et al., 1987).

\subsection{Reading as a Visual Task}

Reading in both print and electronic been a prevalent task nowadays. The reading of electronic or printed signage was a complex process that involves decoding and verbal comprehension components in obtaining meaning (Hoover \& Gough, 1990a). Reading can be defined as the ability to collect information from the pages seen and the skill to understand the text read by a person (Rayner \& Pollatsek, 1989). It is crucial to assess the reading performance, and it must be performed as a routine optometric examination. Reading speed, in words per minute, is a measurement of reading performance, characterized by the number of correct words read per minute. A few components involved reading speed, such as angular character size, contrast, and text and background colors. By of these parameters, there is a difference between the printed and electronic text. Electronic text applying the self-luminance surface compared the printed, which reflected the luminance from the external light source such as room light or streetlight. So, an electronic surface's luminance variability is much higher than the printed (Minkoo Kim et al., 2018). The reading involves both visual and non-visual factors such as motor coordination, motivation, and cognitive skills. In ordinary people, word recognition was done automatically when the reader reads. However, when a person had a visual impairment, an extra effort must be taken to identify words. The ability to read was essential both at a distance and near. For distance, the performance includes reading road or warning signs when driving. People who are good at reading can drive well and know which direction to go. For near performance, likes reading price tags, medicine bottles, or writing also requires good reading skills. A slower reading rate was reported in $63 \%$ of low vision students than commonly sighted students (Omar \& Mohammed, 2005). This finding was consistent with other results from Legge et al., which claimed that low vision subjects' reading speed was slower, although an optimal reading text was given (Legge et al., 1985).

\subsection{Lighting and Visual Effect}

Reading rates were assessed for luminance-matched stimuli with different colors. The colored text was shown on black backgrounds or black text on a colored background. There were no effects of color on reading speed for customarily sighted subjects under photopic conditions, except near the acuity limit (Legge \& Rubin, 1986). While in another study, reading speed was compared to black ink on white paper and ten combinations of colored inks and colored paper. Black ink on white paper showed rapid reading speed compared to other color combinations (Tinker \& Paterson, 1931). Therefore, color revealed an essential aspect of reading speed. People with poor contrast perception degrade driving performance, but they will also have trouble with mobility and increase the risk of falls. A study reported that fall risk was associated with impairment in distant vision among community-dwelling (Ivers et al., 1998) and institutionalized older people. However, Lord, Clark \& Webster did not support the findings, especially when age is adjusted (Lord et al., 1991). They believe that distant vision impairment was not a significant risk of falls among older age groups. Besides, the test of edge-contrast sensitivity was found to be a better predictor for falls than VA (Lord \& Dayhew, 2001). This test measures under low contrast the ability to determine the edges and determine people's ground-level hazards. From the result, if the person detected with loss of edge-contrast sensitivity, older people especially will tend to trip over the obstacles and face hazards at home and outdoor, for instance, steps, curbs, pavement cracks, and misalignment. The above findings showed that it was crucial to determine the ability to detect low contrast hazards to maintain balance and prevent falls among older people.

While outdoor, electronic message signs are widely used as the alternative interface to deliver the road user information. Electronic interface reading is usually associated with common causes of eye-related symptoms, called visual fatigue. Visual fatigue, also known as eye strain, was defined as a subjective visual disturbance. A high degree of visual discomfort usually occurs after prolonged visual activity, manifested by fatigue, pain around the eyes, blurred vision, or headaches. According to Benedetto et al., high screen luminance exhibited a lower blinking rate than low screen luminance (Benedetto et al., 2014). This result was consistent with Rosenfield's study, where a higher level of light intensity contributed to reducing in blinking rate. Thus, an increase in tear evaporation rate was associated 
with dry eyes (Rosenfield, 2011). The effect of reduced luminance can have a profound effect on the ability to do daily activities. Besides, a decrease in luminance is affected by age and ocular diseases such as cataracts, diabetic retinopathy, and age-related macular degenerations. Simple tasks, such as driving, were becoming more challenging to perform. Common complaints from the low-contrast people had difficulty driving at dawn, dusk, fog, or rain. Wood \& Owens had made a study using a video-driving simulator. It was found that subjects had a difficult phase in determining vehicles' speed in the scene when the contrast was reduced. Besides, when the subject viewed the same scene under high and low contrast, they claimed that vehicles moved at lower speed under low contrast (Wood \& Owens, 2005). This condition was dangerous for the driver and also might cause road accidents.

Apart from the critical aspect of electronic reading on the electronic message signs, this study aimed to investigate the color space and contrast effect of the electronic message on reading speed in a lab simulation.

\subsection{Methodology}

\subsection{Sample size}

Twenty-two subjects were recruited using convenient sampling. The sample size was calculated using the sample size formula stated by Naing (2003) as in Equation 1.

$$
\begin{aligned}
& \mathrm{n}=(\mathrm{Z} / \Delta)^{2 \star} \mathrm{P}(1-\mathrm{P}) \\
& \mathrm{n}=(1.96 / 0.18)^{2 \star} 0.238(1-0.238) \\
& \approx 22
\end{aligned}
$$

The inclusion criteria for subject recruitment included habitual binocular visual acuity of $6 / 6$ with no known ocular and general health problems. Informed consent was obtained before participation. This cross-sectional study adhered to the Declaration of Helsinki and was approved by the Institutional Review Board Research Ethic Committee.

\subsection{Electronic Message Construction}

Four texts of sixty-three words were composed using sentences extracted from primary school level five textbooks in the Malay language. Variation in text difficulty was tested in a preliminary study to confirm no statistical difference for interchangeable usage in the main study $[F=0.49, p>0.05$ ). The text was constructed using the font "Highway Gothic" in Microsoft Office PowerPoint 2011 projected via a digital projector. The font type was selected based on the Standard Highway Alphabet by the Federal Highway Administration (FHWA) (Dobres et al., 2017). The text color was black. Text alignment used was formatted as "justified". Text projected were equivalent to 6/14 Snellen Notation or the Logarithm of the Minimum Angle of Resolution - LogMAR 0.8. The text was chosen at random to be tested to minimize the confounding effect of memorization.

\subsection{Color Space Composition}

Color Space was composed using a MacBook Pro [Model A1425]. Color space was measured by "RGB Sliders" from the menu "Transparency" in the Microsoft Office PowerPoint 2011. The RGB slider automatically reads the color space in three values of red, green, and blue. The foreground black color was keyed in as $\mathrm{R}=0, \mathrm{G}=0$, and $\mathrm{B}=0$. These values were then imported to the Color Contrast Analyzer (https://www.sbwfc.co.kr/color-contrast-checker/\#section-middle) to verify the color difference and brightness difference. This value showed the standardization of color parameters used in the text L1 to L4. Transparency levels were set at 25\% (L1), 50\% (L2), $75 \%(\mathrm{~L} 3)$, and $100 \%$ (L4) to simulate different color spaces.

\subsection{Contrast Ratio Formulation}

The luminance was measured by luminance meter LS110 Luminance Meter (Konica Minolta, Japan), as verification from the output values in color space composition among the text L1 to L4. The composition of visible luminance spectral from 380 to $780 \mathrm{~nm}$ was also measured by the CL500A Illuminance Spectrophotometer (Konica Minolta, Japan) to verify the effect of the broadness of spectrum in L1 to L4. There was a black circle on each slide that correlated color intensity with the text. The aperture of measurement was about $4.8 \mathrm{~mm}$ in diameter. The measurement of luminance was measured at the black circle and the background. Michelson Contrast was calculated based on the Lmin (luminance minimum at font/back circle) and Lmax (luminance maximum at the background) measurement formula, as in Equation 2.

$$
\text { Contrast }=\left(L_{\max }-L_{\min }\right) /\left(L_{\max }+L_{\min }\right)
$$

\subsection{Reading Speed Measurement}

Each subject was asked to read aloud the text presented at random order. The voices of subjects were recorded using a voice recorder. Time is taken to complete each text, and numbers of correct words were recorded. The reading speed was recorded as words per minute. 


\subsection{Findings}

Our findings on color space, contrast ratio, and reading speed were summarized in Table 1. L4 recorded the highest number of color differences, brightness differences, and contrast ratios, while the L1 displayed the lowest. The luminance contrast slightly increased from $L 1$ to $L 4\left(0.73 \mathrm{~cd} / \mathrm{m}^{2}\right.$ to $\left.0.86 \mathrm{~cd} / \mathrm{m}^{2}\right)$. The reading speed varied significantly in the four different color spaces (Analysis of Variance: $F(3,84)=2.83, p<0.05)$. Tukey post hoc analysis revealed that the mean reading speed statistically significantly higher from $L 4$ to $L 3$, a mean increase of $18.52 \mathrm{wpm}, 95 \% \mathrm{Cl}[0.81,36.23], \mathrm{p}<0.05$.

However, there was no statistically significant increase in reading speed from $L 1$ to $L 2(\mathrm{M}=1.937$ wpm, $95 \% \mathrm{Cl}[-4.68,8.56]$, $p>0.05), L 1$ to $L 4(M=5.69$ wpm, $95 \% \mathrm{Cl}[-4.34,15.72], p>0.05$ and also $\mathrm{L} 2$ to $L 4(\mathrm{M}=3.75$ wpm, $95 \% \mathrm{Cl}[-6.03,13.55], p<0.05)$. The spectral power distribution was displayed in Figure 1. The relative spectral power of four luminance slides exhibited different relative power of amplitudes, even though there were similar patterns of spectral power distribution.

Table 1. Summary of Color Space, Contrast Ratio, and Reading Speed.

\begin{tabular}{|c|c|c|c|c|c|c|c|c|c|c|c|}
\hline & \multirow{2}{*}{$\begin{array}{l}\text { Pre-determined } \\
\text { transparency level }\end{array}$} & \multirow{2}{*}{ Electronic Text } & \multicolumn{3}{|c|}{ Color Space } & \multirow{2}{*}{$C D$} & \multirow{2}{*}{$\mathrm{BD}$} & \multirow{2}{*}{\multicolumn{2}{|c|}{ Luminance $\left(\mathrm{cd} / \mathrm{m}^{2}\right)$}} & \multirow{2}{*}{ Contrast Ratio } & \multirow{2}{*}{$\begin{array}{c}\text { Reading } \\
\text { speed (wpm) }\end{array}$} \\
\hline & & & $R$ & $G$ & $B$ & & & & & & \\
\hline \multirow{2}{*}{ L1 } & \multirow{2}{*}{$25 \%$} & Foreground & 0 & 0 & 0 & \multirow[t]{2}{*}{516} & \multirow[t]{2}{*}{172} & $L_{\max }$ & $86.47 \pm 0.31$ & \multirow[t]{2}{*}{0.73} & \multirow[t]{2}{*}{$144.66 \pm 23.69$} \\
\hline & & Background & 172 & 172 & 172 & & & $\mathrm{~L}_{\min }$ & $13.67 \pm 0.02$ & & \\
\hline \multirow{2}{*}{ L2 } & \multirow{2}{*}{$50 \%$} & Foreground & 0 & 0 & 0 & \multirow[t]{2}{*}{596} & \multirow[t]{2}{*}{199} & $L_{\max }$ & $119.37 \pm 0.38$ & \multirow[t]{2}{*}{0.79} & \multirow[t]{2}{*}{$142.72 \pm 21.08$} \\
\hline & & Background & 199 & 199 & 199 & & & $L_{\min }$ & $13.90 \pm 0.01$ & & \\
\hline \multirow{2}{*}{ L3 } & \multirow{2}{*}{$75 \%$} & Foreground & 0 & 0 & 0 & \multirow[t]{2}{*}{681} & \multirow[t]{2}{*}{227} & $L_{\max }$ & $167.23 \pm 0.78$ & \multirow[t]{2}{*}{0.84} & \multirow[t]{2}{*}{$157.49 \pm 23.33$} \\
\hline & & Background & 227 & 227 & 227 & & & $L_{\min }$ & $14.68 \pm 0.04$ & & \\
\hline \multirow{2}{*}{ L4 } & \multirow{2}{*}{$100 \%$} & Foreground & 0 & 0 & 0 & \multirow[t]{2}{*}{765} & \multirow[t]{2}{*}{255} & $L_{\max }$ & $206.13 \pm 0.81$ & \multirow[t]{2}{*}{0.86} & \multirow[t]{2}{*}{$138.97 \pm 21.44$} \\
\hline & & Background & 255 & 255 & 255 & & & $\mathrm{~L}_{\min }$ & $15.01 \pm 0.01$ & & \\
\hline
\end{tabular}

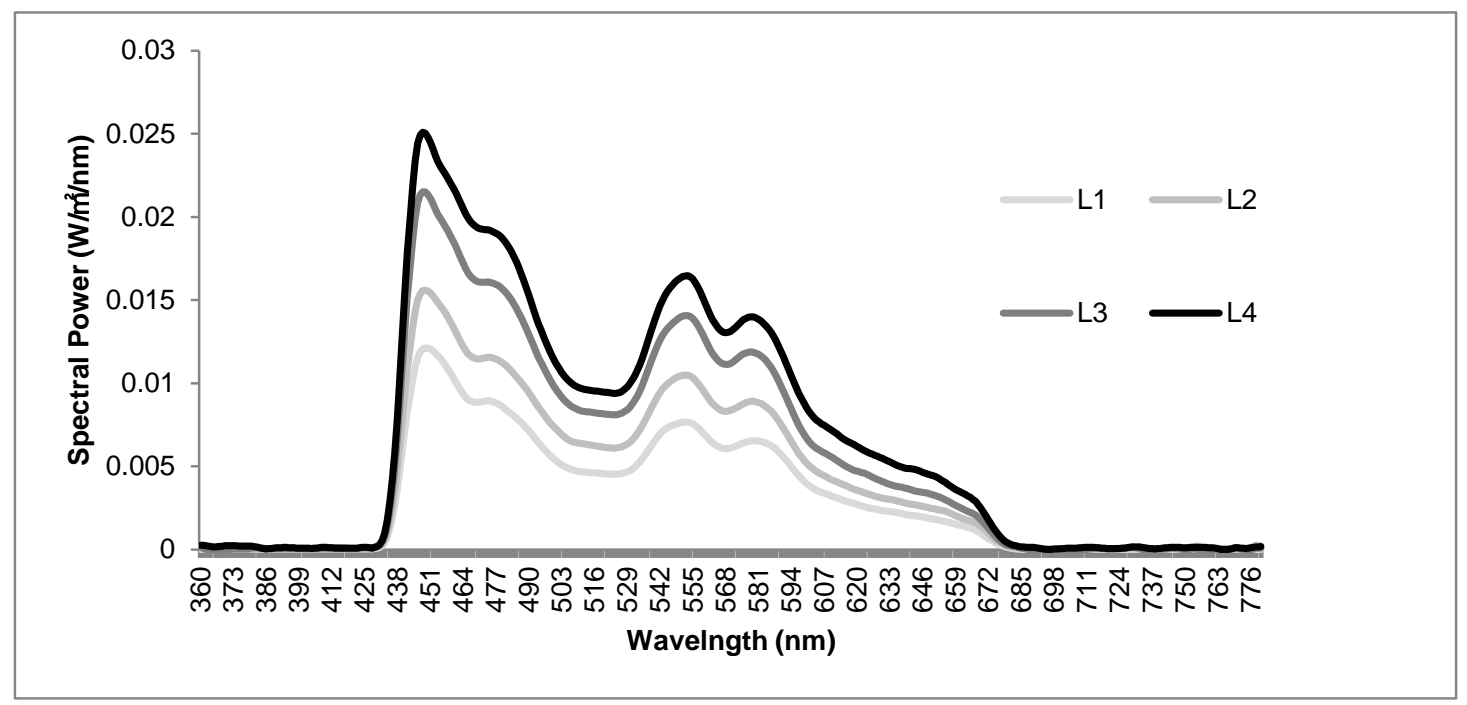

Fig. 1. The spectral power distribution of four different luminance slide presentation.

\subsection{Discussion}

Our findings revealed that the highest reading speed was recorded in intermediate color space at $75 \%$ transparency. Our findings suggested that contrast might not be the only determining factor in reading performance. Our study's contrast ratio is quite similar for $L 1$ to L4, but the color space varied. Our findings agreed with previous studies (Mansfield et al., 1996; Rubin, 2013). A recent study on the linear model based on the temporal impulse responses under different light levels suggested that visual comfort changes cannot be fully explained by the sufficient luminance contrast of the stimuli (Yoshimoto et al., 2020). Visual discomfort occurs when the retinal image departs from natural scenes. Uncomfortable stimuli are processed with a more massive and less sparse neural response (Wilkins, 2015). Uncomfortable visual stimuli usually cause the visual cortex to undergo large oxygenation, consistent with inefficient neural encoding. The neural computation that sustains sight is more complicated when the visual scene is spatially periodic. The color contrast is high or when saccadic suppression is impaired by a flicker that is too rapid to be seen.

The maximum reading speed was found in $\mathrm{L} 3$ at approximately $158 \mathrm{wpm}$. This value was very similar to the previous reading speed (164 wpm for contextual sentences) in the Malaysian population (Chen et al., 2019). The speed of reading is reduced under lower luminance than high luminance (Benedetto et al., 2014). The reading speed reduced at the highest contrast (L4) might be due to disability glare. The glare from the background may have interfered with the clarity of the text while reading. The effect of the "luminous veil" reduces the retina's contrast (Flynn \& Badano, 1999). This effect may have transpired as the bright illumination of the projector in a dark room. It mimics the condition when people perceive high-glare conditions such as sunlight or approaching high luminance sources, such as car headlights or advertisement backlights at night, decreasing text visibility (Anstey et al., 2005; Wolf, 1974). 
Based on the color checker's web base calculator, all the slides were considered to have the right contrast conditions. The color difference was above 500 , the brightness difference was above 125 , and the contrast ratio was above 7 . If the brightness difference is above 125, the color is considered adequate light/dark contrast. If the color difference was more than 500 , then the hue contrast is adequate. Whereas equal or less than 500 would mean that the hues might be indistinguishable. In this reading performance experiment, we used neutral color to evade chromaticity adaptation. When a luminance meter was used to confirm the display's luminosity, we found that the translucency indicator is ambiguous. While the transparency was set at $25 \%$ and $50 \%$, the luminance meter recorded almost three times higher from L1 to L2. Comparing L3 and L4, the luminance contrasts were closer to the transparency value of $75 \%$ and $100 \%$, respectively. The ocular effect of spectral power distribution was reported in different light sources and filters (Chung \& Pease, 1999). Shorter wavelength has been associated with smaller pupil sizes (Lewis, 1999). Variation in pupil size can affect visibility due to the depth of focus and glare factor. Based on the relative spectral power distribution, a uniform reduction of spectral power was observed from the highest contrast (L4) to the lowest contrast (L1).

\subsection{Conclusion}

The virtually calculated contrast is different from direct luminance measurement in electronic message signs. Transparency indicators generated by electronic devices and direct contrast measurements using luminance meter are dissimilar. The highest reading speed was found at the intermediate color space. The human visual factors such as glare might be the essential issues related to the electronic related message sign. Efficiency in retrieving information from signage is essential for safe driving. Therefore, a more comprehensive investigation of electronic message signs is needed.

\section{Acknowledgments}

Financial support: Multidiscipline Grant Fund [600-IRMI/MYRA 5/3/MITRA (007/2017 \& 007/2017)-2].

\section{References}

Anstey, K. J., Wood, J., Lord, S., \& Walker, J. G. (2005). Cognitive, sensory and physical factors enabling driving safety in older adults. Clinical Psychology Review, 25(1), 45-65.

Benedetto, S., Carbone, A., Drai-Zerbib, V., Pedrotti, M., \& Baccino, T. (2014). Effects of luminance and illuminance on visual fatigue and arousal during digital reading. Computers in Human Behavior, 41, 112-119.

Boyce, P., \& Wilkins, A. (2018). Visual discomfort indoors. Lighting Research \& Technology, 50(1), 98-114.

Buchner, A., Mayr, S., \& Brandt, M. (2009). The advantage of positive text-background polarity is due to high display luminance. Ergonomics, 52(7), 882-886.

Chen, A.-H., Khalid, N. M., \& Buari, N. H. (2019). Age factor affects reading acuity and reading speed in attaining text information. International Journal of Ophthalmology, 12(7), 1170-1176. PubMed.

Chung, S. T. L., \& Pease, P. L. (1999). Effect of yellow filters on pupil size. Optometry \& Vision Science, 76(1), 59-62.

Dobres, J., Chrysler, S. T., Wolfe, B., Chahine, N., \& Reimer, B. (2017). Empirical Assessment of the Legibility of the Highway Gothic and Clearview Signage Fonts. Transportation Research Record, 2624(1), 1-8.

Duchnicky, R. L., \& Kolers, P. A. (1983). Readability of text scrolled on visual display terminals as a function of window size. Human Factors: The Journal of the Human Factors and Ergonomics Society, 25(6), 683-692.

Flynn, M. J., \& Badano, A. (1999). Image quality degradation by light scattering in display devices. Journal of Digital Imaging, 12(2), 50-59. Hoover, \& Gough. (1990a). The simple view of reading. Reading Writing, 2, 127-160.

Hoover, W. A., \& Gough, P. B. (1990b). The simple view of reading. Reading and Writing, 2(2), 127-160.

Ivers, R., Cumming, R., \& Mitchell, P. (1998). Visual impairment and falls in older adults: The Blue Mountains Eye Study. Journal of the American Geriatrics Society, 46, 58-64.

Jaiswal, S., Asper, L., Long, J., Lee, A., Harrison, K., \& Golebiowski, B. (2019). Ocular and visual discomfort associated with smartphones, tablets and computers: What we do and do not know. Clinical \& Experimental Optometry.

Jufri, S., Buari, N. H., \& Chen, A.-H. (2016). Text structures affect reading speed. Social and Management Research Journal, 13(1), 118-131.

Khalid, N. M., Buari, N. H., \& Chen, A.-H. (2017). Comparison of Oral Reading Errors between Contextual Sentences and Random Words among Schoolchildren. International Education Studies, 10(1), 47-55.

Legge, G E, Parish, D. H., Luebker, A., \& Wurm, L. H. (1990). Psychophysics of reading. XI. Comparing color contrast and luminance contrast. Journal of the Optical Society of America. A, Optics and Image Science, 7(10), 2002-2010.

Legge, G E, \& Rubin, G. S. (1986). Psychophysics of reading. IV. Wavelength effects in normal and low vision. J. Opt. Soc. Am. A 3, 40-51. 
Legge, G E, Rubin, G. S., \& Luebker, A. (1987). Psychophysics of reading. V. The role of contrast in normal vision. Vision Res. 27, 1165-1177.

Legge, G E, Rubin, G. S., Pelli, D. G., \& Schkeske, M. M. (1985). Phychophysics of reading—II. Low Vision. Vision Research.

Legge, Gordon E., Ahn, S. J., Klitz, T. S., \& Luebker, A. (1997). Psychophysics of reading—XVI. The visual span in normal and low vision. Vision Research, 37(14), 19992010.

Lewis, A. (1999). Visual performance as a function of spectral power distribution of light sources used for general outdoor lighting. Journal of the Illuminating Engineering Society, 28(1), 37.

Lord, S., Clark, R., \& Webster, I. (1991). Visual acuity and contrast sensitivity in relation to falls in an elderly population. Age Ageing, 175-181. Lord, S., \& Dayhew, J. (2001). Visual risk factors for fall. J Am Geriatr Soc, 508-515.

Mansfield, J. S., Legge, G. E., \& Bane, M. C. (1996). Psychophysics of reading. XV: Font effects in normal and low vision. Investigative Ophthalmology \& Visual Science, $37(8), 1492-1501$.

Minkoo Kim, Dong-Hwan Jeon, Jeong-Sik Kim, Byung-Chang Yu, YungKyung Park, \& Seung-Woo Lee. (2018). Optimum display luminance depends on white luminance under various ambient illuminance conditions. Optical Engineering, 57(2), 1-9.

Najmee, N. A. A., Rosli, S. A., \& Jalaludin, S. B. (2020). The Accommodation Response and Facility between Children and Young Adults. Environment-Behaviour Proceedings Journal, 5(14), 111-118.

Nooree $\mathrm{Na}$, \& Hyeon-Jeong Suk. (2014). Adaptive luminance contrast for enhancing reading performance and visual comfort on smartphone displays. Optical Engineering, 53(11), $1-7$.

Omar, R., \& Mohammed, Z. (2005). Relationship between vision and reading performance among low vision students. International Congress Series, 1282, 679-683. Rayner, K., \& Pollatsek, A. (1989). The Psychology of Reading. Prentice Hall, New Jersey.

Rosenfield, M. (2011). Computer vision syndrome: A review of ocular causes and potential treatments. Ophthalmic and Physiological Optics, 31(5), 502-515. Rubin, G. S. (2013). Measuring reading performance. Vision Research, 90, 43-51.

Taylor, T., Pradhan, A., Divekar, G., Romoser, M., Muttart, J., Gomez, R., Pollatsek, A., \& Fisher, D. L. (2013). The view from the road: The contribution of on-road glancemonitoring technologies to understanding driver behavior. Accident Analysis \& Prevention, 58, 175-186.

Tinker, M A, \& Paterson, D. G. (1931). Studies of typographical factors influencing speed of reading. VII. Variations in color of print and background. J. Appl. Psychol 15, $471-479$.

Tinker, Miles A, \& Paterson, D. G. (1931). Studies of typographical factors influencing speed of reading. VII. Variations in color of print and background. Journal of Applied Psychology, 15(5), 471.

Wilkins, A. (2015). A physiological basis for visual discomfort: Application in lighting design. Lighting Research \& Technology, 48(1), 44-54.

Wolf, E. (1974). Intraocular Light Scattering: Theory and Clinical Application. Archives of Ophthalmology, 91(4), 333.

Wood, J. M., \& Owens, D. A. (2005). Standard measures of visual acuity do not predict drivers' recognition performance under day or night conditions. Optom Vis Sci, $82,698-705$.

Yoshimoto, S., Jiang, F., Takeuchi, T., Wilkins, A. J., \& Webster, M. A. (2020). Visual discomfort from flicker: Effects of mean light level and contrast. Vision Research, $173,50-60$. 